\title{
Occurrence of senescence-escaping cells in doxorubicin-induced senescence is enhanced by PD0332991, a cyclin-dependent kinase 4/6 inhibitor, in colon cancer HCT116 cells
}

\author{
KUNIO KITADA, FENGLING PU and MASAKAZU TOI \\ Department of Breast Surgery, Graduate School of Medicine, Kyoto University, Kyoto 606-8507, Japan
}

Received April 19, 2018; Accepted October 15, 2018

DOI: $10.3892 / 01.2018 .9657$

\begin{abstract}
Cancer treatment induces cellular senescence, and it is considered to be one of the factors that determines treatment outcome. Senescence can be efficiently induced in cultured cells by DNA-damaging drugs, including doxorubicin (DOX), cisplatin and etoposide. Cells in senescence cease proliferation; however, it has been demonstrated that colonies that are formed from cells escaping senescence appear in drug-induced senescence; however, the conditions influencing the emergence of such senescence-escaping cells (SECs) remain unclear. The present study aimed to investigate the relevance of the cell cycle phase and colony formation in the DOX-induced senescence of human colon cancer HCT116 cells. After release from serum starvation in the presence of DOX, cells synchronously progressed through the cell cycle and were arrested in the $G_{1}$ and $\mathrm{G}_{2} / \mathrm{M}$ phases. The ratio of $\mathrm{G}_{1}$ cells arrested immediately by the treatment of $G_{1}$ phase cells was positively associated with the number of colony-forming cells. A procedure increasing $\mathrm{G}_{1}$-treated $\mathrm{G}_{1}$-arrested cells enhanced colony formation. Co-treatment of PD0332991 with DOX slowed progression of cells in the $\mathrm{G}_{1}$ phase resulting in enhanced colony formation from the increased $G_{1}$-treated $G_{1}$-arrested cells. These results may provide useful insights into understanding the emergence of SECs in drug-induced senescence.
\end{abstract}

\section{Introduction}

Cells in senescence are metabolically active and exhibit senescence-specific phenotypes, including a senescence-associated secretory phenotype $(1,2)$. These include the morphological changes in cells being flattened and enlarged, induction of senescence-associated $\beta$-galactosidase (SA- $\beta$-Gal) activity and secretion of proinflammatory cytokines, including interleukin (IL)-6 and IL-8. IL-6 and IL- 8 have been demonstrated to

Correspondence to: Dr Kunio Kitada, Department of Breast Surgery, Graduate School of Medicine, Kyoto University, 54 ShogoinKawahara, Sakyo, Kyoto 606-8507, Japan

E-mail:kitadakno59@gmail.com

Key words: cellular senescence, senescence-escaping cells, cell cycle, PD0332991, doxorubicin exhibit dual functions in cancer development (3). Although senescent cells stay alive, they do not proliferate. The induction of senescence in cancer cells has previously been established as one of the factors determining the overall outcome of cancer treatment, and may represent a potential strategy to suppress cancer growth $(4,5)$. When used at low concentrations, a variety of chemicals, including DNA-damaging drugs, including doxorubicin (DOX), etoposide, cisplatin and camptothecin, are known to induce senescence in cancer cells $(6,7)$. For example, in in vitro settings, senescence is induced in cancer cells by treating cells with DOX for $24 \mathrm{~h}$ at submicromolar concentrations followed by subsequent incubation in DOX-free medium (8-10). DOX inhibits the proliferation of cancer cells by inducing senescence, although this does not immediately kill cancer cells. However, the efficiency of the induction cannot reach $100 \%$ and a number of colonies appear in the incubation $(9,10)$. These colonies are considered to be generated from cells escaping from senescence. It would be of clinical value to understand which conditions can produce such senescenceescaping cells (SECs), as the occurrence of SECs can significantly influence the outcome of chemotherapy. In the present study, the relevance of cell cycle phases of cells treated with DOX and the occurrence of SECs was examined by monitoring colony formation in DOX-induced senescence.

Cyclin-dependent kinase 4/6 (Cdk4/6) inhibitors, including PD0332991, LEE011 and LY2835219, have been used in cancer treatment $(11,12)$. Cdk4/6 has previously been demonstrated to be required for the activation of $\mathrm{Cdk} 2$, which acts as a key protein kinase for the transition from the $G_{1}$ to $S$ phase $(13,14)$. Therefore, blocking Cdk4/6 is expected to lead to cell cycle arrest at the $G_{1}$ phase. Indeed, $G_{1}$ arrest has been reported to occur in cells treated with Cdk4/6 inhibitors $(15,16)$. Since the cell cycle resumes following the removal of the inhibitors, immediate cell death is not observed (17-19). On the one hand, cell cycle arrest at the $G_{1}$ phase is required for the induction of senescence $(20,21)$. Therefore, blocking the cell cycle by the inhibitors may promote DOX-induced senescence and reduce the occurrence of SECs. In the present study, this assumption was tested using PD0332991, one of the Cdk4/6 inhibitors.

\section{Materials and methods}

Cell lines and cultures. The human colon cancer HCT116 cell line was obtained from the Riken Cell Bank (Tsukuba, Japan), 
and was cultured in McCoy's 5A medium (Sigma-Aldrich; Merck KGaA, Darmstadt, Germany) containing 10\% fetal bovine serum (FBS; Sigma-Aldrich; Merck KGaA). Penicillin and streptomycin (1\%) antibiotics (Thermo Fisher Scientific, Inc., Waltham, MA, USA) were added to the culture medium. Cells were grown at $37^{\circ} \mathrm{C}$ with $5 \% \mathrm{CO}_{2}$ in a humidified incubator.

Reagents. Doxorubicin (DOX; $6 \mathrm{mM}$ stock in water; Sigma-Aldrich; Merck KGaA), nocodazole (5 mg/ml stock in DMSO; catalog no. 487928; EMD Millipore, Billerica, MA, USA), PD0332991 (5 mM stock in DMSO; catalog no. S1116; Selleckchem, Houston, TX, USA) and Giemsa solution (catalog no. GS500; Sigma-Aldrich; Merck KGaA) were used. DOX and PD0332991 were used at various concentrations (200 and $400 \mathrm{nM}$ for DOX; 50, 100, 200, 400, and $800 \mathrm{nM}$ for PD0332991), which are expressed as D and PD plus numbers, respectively. For instance, D200 and PD200 represent $200 \mathrm{nM}$ of DOX and PD0332991, respectively, and D_00 and PD_00 represent the vehicle of each reagent.

Induction of senescence. A total of $1.5 \times 10^{6}$ HCT116 cells were pre-cultured in 6-well plates for $24 \mathrm{~h}$. The cells were subsequently washed twice with PBS and then incubated in serum-free medium (McCoy's 5A without FBS) for $24 \mathrm{~h}$. The serum-free medium was replaced with the standard medium (McCoy's 5A with FBS) containing DOX and the cells were incubated for an additional $24 \mathrm{~h}$ in the aforementioned culture conditions. Cells were then washed twice with PBS and were incubated in $2.5 \mathrm{ml} \mathrm{DOX}$-free standard medium at $37^{\circ} \mathrm{C}$. Every day $1 \mathrm{ml}$ of the culture medium was replaced with $1 \mathrm{ml}$ of fresh standard medium. This procedure is designated as the standard (STD) procedure. For the pre-release (Pre-REL) procedure, an additional 3-4 h DOX treatment was performed prior to release from serum starvation. For the post-release (Post-REL) procedure, the $24 \mathrm{~h}$ DOX treatment was performed at 5-6 $\mathrm{h}$ post-release from serum starvation. The procedures of STD, Pre-REL and Post-REL are illustrated in Fig. 1A.

Colony formation assay. Treated and control cells were harvested and plated on 6-well plates $(3,000,6,000,12,000$ and 24,000 cells per well for treated cells, and 100, 200 and 400 cells per well for control cells). Following a 14-day incubation, colonies were fixed with $100 \%$ methanol for $10 \mathrm{~min}$ at room temperature (RT), stained with Giemsa solution for $1 \mathrm{~h}$ at RT and then counted by eye. Colony formation efficiency (CFE) was expressed as the rate of the number of colonies formed against the number of cells inoculated.

The effect of PD0332991 on CFE was examined in DOX-induced senescence in synchronized cells and unsynchronized growing cells. PD0332991 was co-treated with DOX for $24 \mathrm{~h}$ at $37^{\circ} \mathrm{C}$. Induction of senescence in synchronized cells was performed according to the STD procedure.

SA- $\beta$-Gal staining. Treated and untreated cells growing in 6 -well plates were fixed in 3\% paraformaldehyde for $5 \mathrm{~min}$ at RT and then stained with 5-bromo-4-chloro-3-indolyl- $\beta$ D-galactoside (X-Gal; $1 \mathrm{mg} / \mathrm{ml} ; 50 \mathrm{mg} / \mathrm{ml}$ stock in DMSO; Takara Biotechnology, Inc., Otsu, Japan) at pH 6.0 according to a previously described protocol (22). SA- $\beta$-Gal-positive cells are expressed as percentage of the total number of cells.
Flow cytometry. Treated and untreated cells were harvested and washed with cold PBS, and then fixed overnight in cold $70 \%$ ethanol. Fixed cells were twice washed with PBS and stained with propidium iodide (PI; $0.5 \mu \mathrm{g} / \mathrm{ml}$; catalog no. P4170; SigmaAldrich; Merck KGaA) for $10 \mathrm{~min}$ at RT. The analysis was performed using Accuri C6 flow cytometry (BD Biosciences, San Jose, CA, USA). Cell debris and doublets were eliminated by gating of forward scatter/side scatter and fluorescence (FL)-area/FL-width of PI staining. In total, $>8,000$ cells were collected for each sample.

For cell cycle analysis of cells treated with nocodazole, a final concentration of $100 \mathrm{ng} / \mathrm{ml}$ nocodazole was added into the culture medium $24 \mathrm{~h}$ prior to the harvest for the analysis.

Statistical analysis. Cell cycle histograms are representative of experiments conducted twice in triplicates. Percentages of $\mathrm{G}_{1}$ cells are presented as the mean \pm standard deviation (SD) $(n=3)$. Colony formation analysis was performed at least twice in triplicates. CFE data are presented the mean \pm SD $(n=3)$. One-way ANOVA, followed by Tukey post hoc test, and Pearson's correlation tests were performed in Microsoft Excel 2013 (Microsoft Corporation, Redmond, WA, USA). The P-value of Pearson's correlation was calculated using the TDIST function in Microsoft Excel. $\mathrm{P}<0.05$ was used to indicate a significant difference.

\section{Results}

Colony formation in senescence induced by DOX treatment of cells in different cell cycle phases. It has been reported that cellular senescence can be induced at high efficiency in HCT116 cells by DOX treatment $(9,20)$. Using the previously reported procedure (9), senescence was also induced in $>90 \%$ of HCT116 cells in the present study (data not shown). In addition, HCT116 cells have been used for cell cycle analysis due to their highly synchronized progression of the cell cycle $(23,24)$. For these reasons, HCT116 cells were used in the present study.

The cell cycle progression was synchronized by the serumblock/release procedure. Cells in different cell cycle phases were exposed to DOX for $24 \mathrm{~h}$. Following this exposure, the cell cycle was analyzed by flow cytometry and cells were plated in culture dishes containing a DOX-free medium. Following a 14-day incubation, CFE was measured (STD in Fig. 1A). DOX induced cell cycle arrest in the $G_{1}$ and $\mathrm{G}_{2} / \mathrm{M}$ phases (Fig. 1B). Marked amounts of $\mathrm{G}_{1}$-arrested cells appeared with the DOX treatment initiated at 0 and 2 h postrelease from serum starvation (Fig. 1B). Since cells were in the $\mathrm{G}_{1}$ phase at 0-4 h post-release, cells arrested at the $\mathrm{G}_{1}$ phase were considered to be cells immediately arrested by the DOX treatment. This was further confirmed by co-treatment with nocodazole, an $\mathrm{M}$ phase-arresting reagent, which can block the entry of $M$ phase cells into the $G_{1}$ phase in the next round of cell cycle $(25,26)$. The $\mathrm{G}_{1}$-arrested cells were not affected by the addition of nocodazole (data not shown). The rate of $\mathrm{G}_{1}$ arrested cells was found to be significantly correlated with CFE ( $\mathrm{r}=0.975, \mathrm{P}=0.000028$ ) (Fig. 1C). The significant correlation observed strongly suggests that immediate $G_{1}$ arrest of cells in the $G_{1}$ phase by DOX treatment enhances the colony formation ability. It should be noted that CFE was markedly low when DOX treatment was initiated at $4 \mathrm{~h}$ and later after 


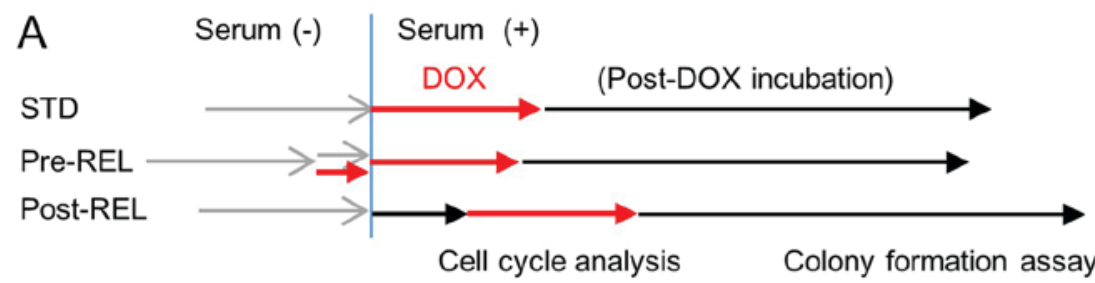

B

Time after release from serum starvation (h)

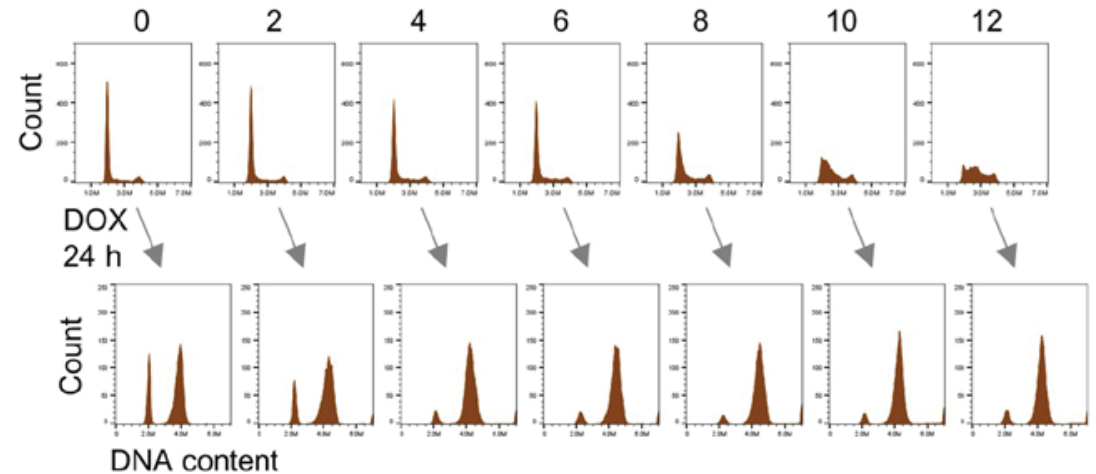

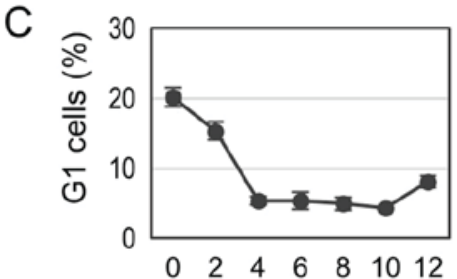

Time after release $(\mathrm{h})$

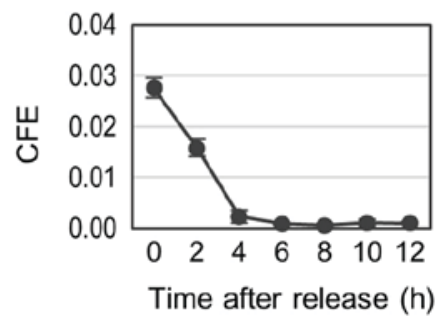

Figure 1. Influence of cell cycle phase on colony formation in DOX-induced senescence. (A) Illustration of three treatment procedures (STD, Pre-REL and Post-REL) to induce senescence in HCT116 cells by DOX. (B) Colony formation was examined in senescence induced by DOX treatment of cells synchronously progressing through the cell cycle. Cells were harvested every $2 \mathrm{~h}$ after release from serum starvation, and cell cycle distribution was analyzed by flow cytometry (upper panel of B). DOX ( $400 \mathrm{nM}$ ) was added into the medium every $2 \mathrm{~h}$ after release from serum starvation. Following a 24-h incubation, cells were harvested and cell cycle distribution (lower panel of B) and $(C)$ percentage of $\mathrm{G}_{1}$ phase cells (upper panel of C) were analyzed by flow cytometry. Simultaneously, the harvested cells were plated on 6-well plates and incubated for 14 days. Colonies formed were counted and expressed as CFE (lower panel of C). CFE, colony formation efficiency; DOX, doxorubicin; Pre-REL, pre-release; Post-REL, post-release; STD, standard.

A

STD
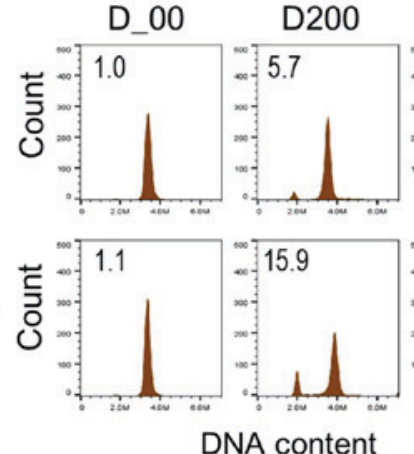

D200
Pre-REL

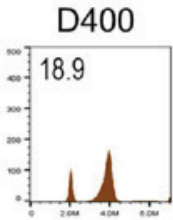

C

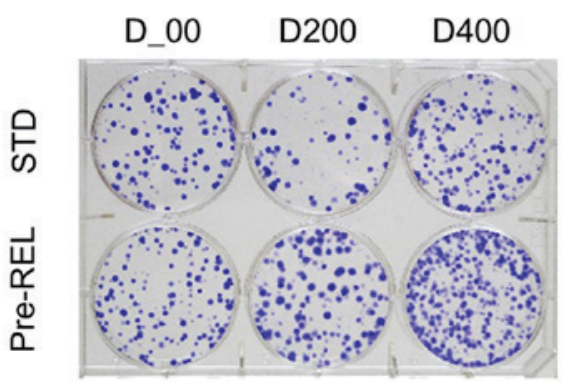

B

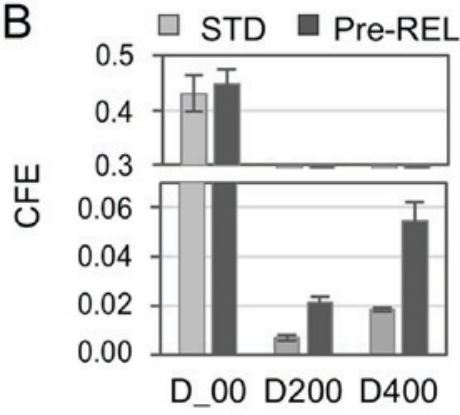

D

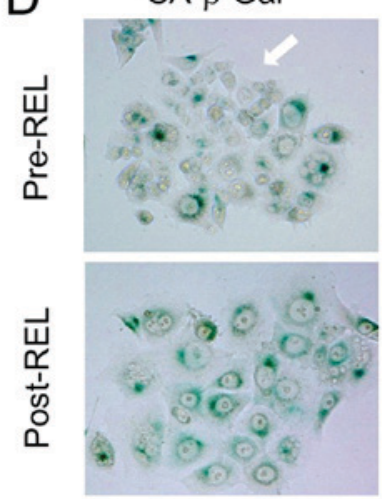

Phase contrast
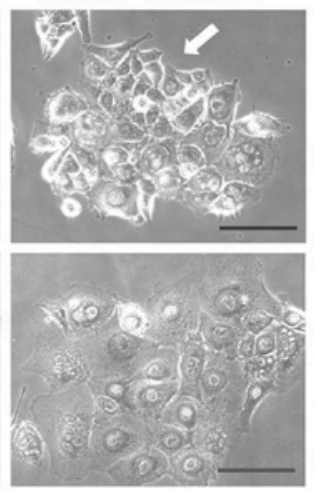

Figure 2. $\mathrm{G}_{1}$ arrest by DOX-treatment of $\mathrm{G}_{1}$ cells enhances CFE in senescence. Cells were treated with $200 \mathrm{nM}$ (D200) and $400 \mathrm{nM}$ (D400) of DOX and DMSO vehicle (D_00). (A) Cell cycle distribution at $24 \mathrm{~h}$ after treatment with DOX analyzed by flow cytometry. The numbers in histograms indicate percentages of $\mathrm{G}_{1}$ cells. For the analysis of cell cycle distribution, nocodazole $(100 \mathrm{ng} / \mathrm{m})$ was added to completely block the cell cycle progression from $\mathrm{M}_{\mathrm{phase}}$ to $\mathrm{G}_{1}$ phase in the next cycle. (B) Cells treated with DOX were incubated in DOX-free medium, and at 14 days of incubation, CFE was determined (expressed as the rate of the number of colonies formed against the number of cells inoculated). (C) Representative images of colonies stained with Giemsa. (D) Representative images of senescent cells of day $3+$ stained with SA- $\beta$-Gal. White arrows indicate colonies consisting of 12 cells. Scale bar, $100 \mu \mathrm{m}$. CFE, colony formation efficiency; DOX, doxorubicin; SA- $\beta$-Gal, senescence-associated $\beta$-galactosidase; Pre-REL, pre-release; Post-REL, post release; STD, standard. 
A

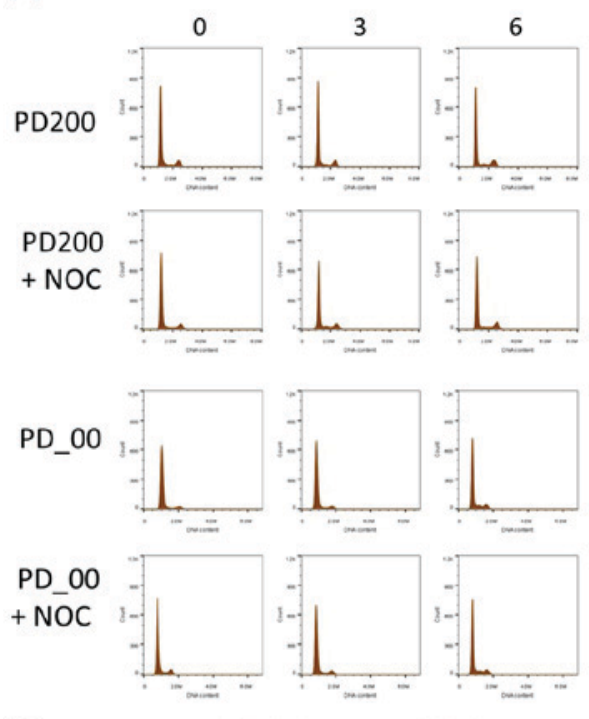

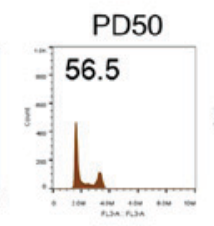

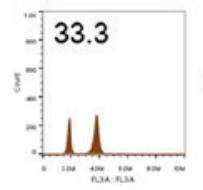

D400 20.8

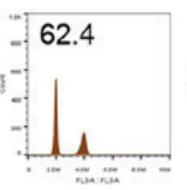

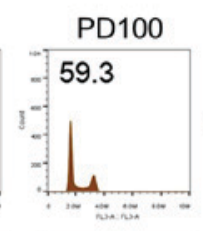
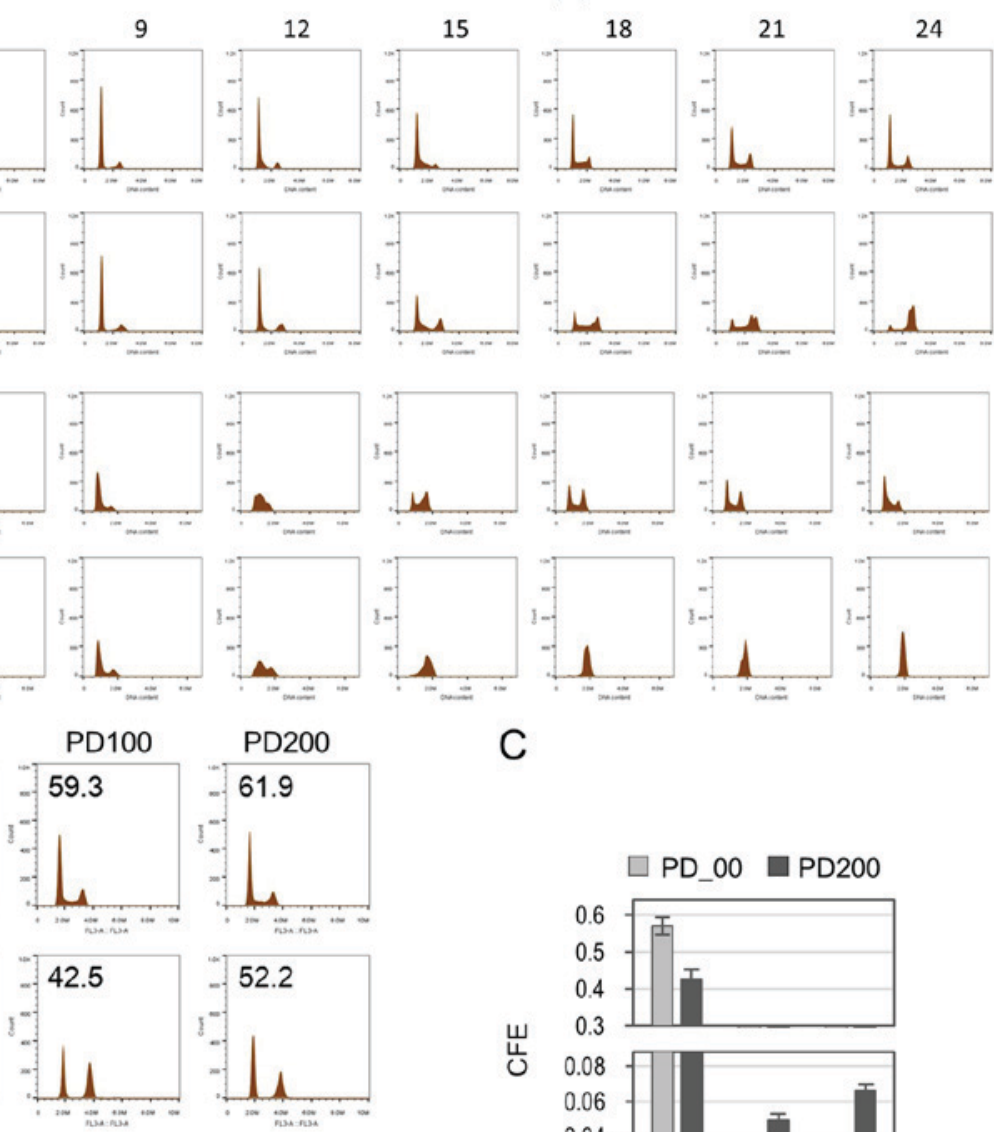

C
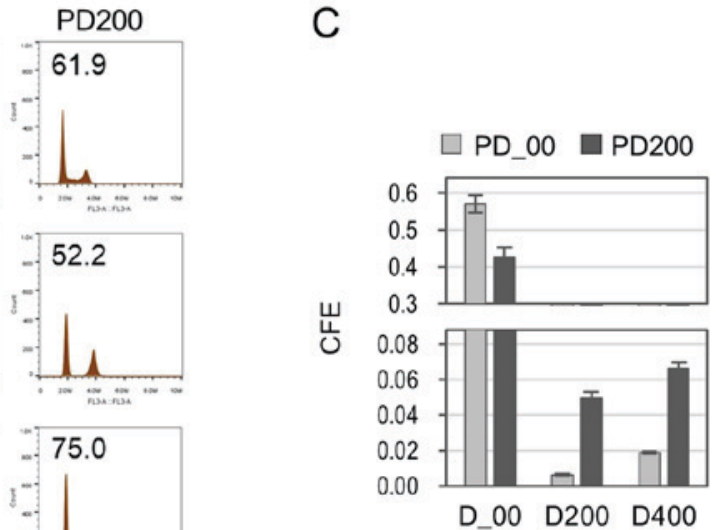

Figure 3. Co-treatment of PD0332991 with DOX in synchronized cells enhances colony formation in induced senescence. (A) Analysis of cell cycle progression affected by PD0332991. Serum-starved cells were released in the presence of 200 nM PD0332991 (PD200) and DMSO vehicle (PD_00) with/without NOC, and then cell cycle progression was analyzed by flow cytometry. (B) DOX-induced $\mathrm{G}_{1}$ arrest affected by PD0332991. Senescence was induced by DOX in the presence of PD0332991. Cell cycle distribution was analyzed $24 \mathrm{~h}$ after release in the presence of various concentrations of DOX and PD0332991. The numbers present in the histograms indicate percentages of $\mathrm{G}_{1}$ cells. (C) Cells treated with DOX and PD0332991 were incubated in drug-free medium to induce senescence. Following a 14-day incubation, CFEs were determined (expressed as the rate of the number of colonies formed against the number of cells inoculated). Vertical and horizontal axes in histograms in (A) and (B) are DNA content and cell count, respectively. NOC, nocodazole; CFE, colony formation efficiency; DOX, doxorubicin.

the release. This represents the Post-REL procedure illustrated in Fig. 1A.

Increase in $G_{l}$-arrested cells by treatment of $G_{l}$ cells enhances CFE in DOX-induced senescence. To further examine the association between $\mathrm{G}_{1}$-treated $\mathrm{G}_{1}$-arrested cells and colony formation, an attempt was made to increase the number of $\mathrm{G}_{1}$-treated $\mathrm{G}_{1}$-arrested cells. Serum-starved cells were pretreated with DOX for 3-4 h prior to release, and the cell cycle and CFE were examined (Pre-REL in Fig. 1A). Cell cycle analysis demonstrated an increase of $\mathrm{G}_{1}$-arrested cells, which was not affected by the addition of nocodazole (Fig. 2A). In accord with the increase, CFE was significantly enhanced (Fig. 2B and C). In addition, cell clusters consisting of $8-15$ cells, which exhibited no SA- $\beta$-Gal activity, were detected at 2-3 days of incubation in the Pre-REL procedure (Fig. 2D). By contrast, in the Post-REL procedure, such cell clusters were not detected in the short-term incubation groups (Fig. 2D).
Co-treatment of PD0332991 with DOX in synchronized cells enhances colony formation in the induced senescence. PD0332991, a CDK4/6 inhibitor, has been demonstrated to inhibit cell cycle progression and arrest cells in $\mathrm{G}_{1}$ phase $(15,16)$. The present study examined the effects of PD0332991 on CFE in DOX-induced senescence. First, cells were arrested in the $G_{1}$ phase by serum starvation and then released from the $\mathrm{G}_{1}$ block by medium replacement. PD0332991 was added at the release from serum starvation and the cell cycle progression was monitored by flow cytometry (Fig. 3A). Compared with the control, PD0332991 delayed the progression of cells from the $G_{1}$ to $S$ phase. This was confirmed in the cell cycle histograms of cells when co-treated with a mitotic inhibitor nocodazole (+ NOC in Fig. 3A). The $G_{1}$ peak gradually decreased in the incubation and contrastingly, the $G_{2} / M$ peak increased. Next, the effects of this slow cell cycle progression in the $G_{1}$ phase on DOX-induced senescence were examined. Senescence was induced in cells by DOX treatment in the 
A
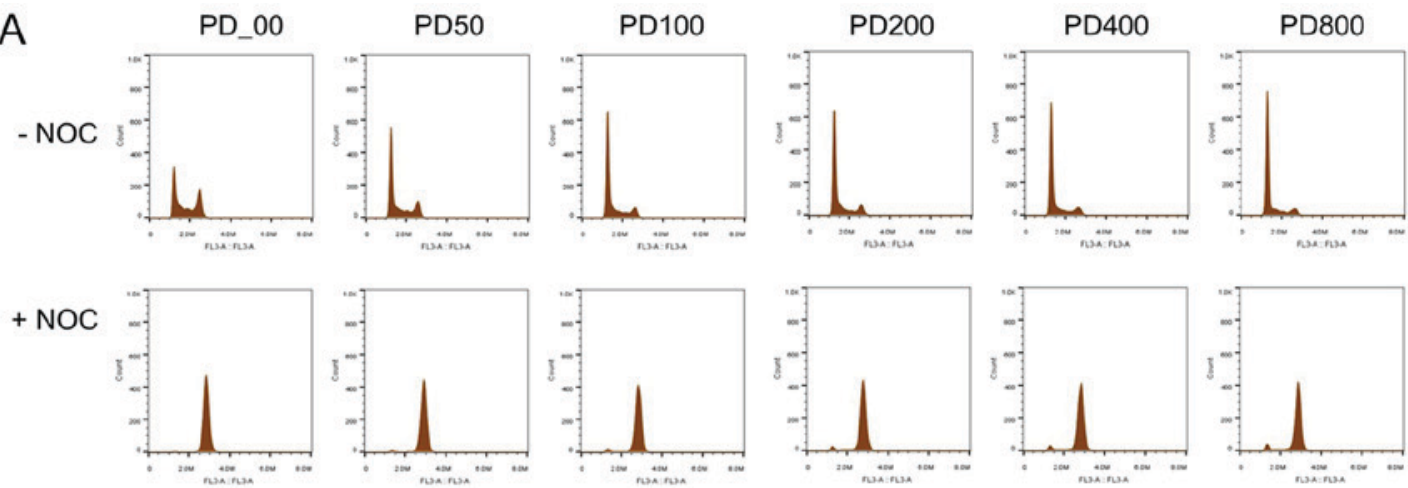

B
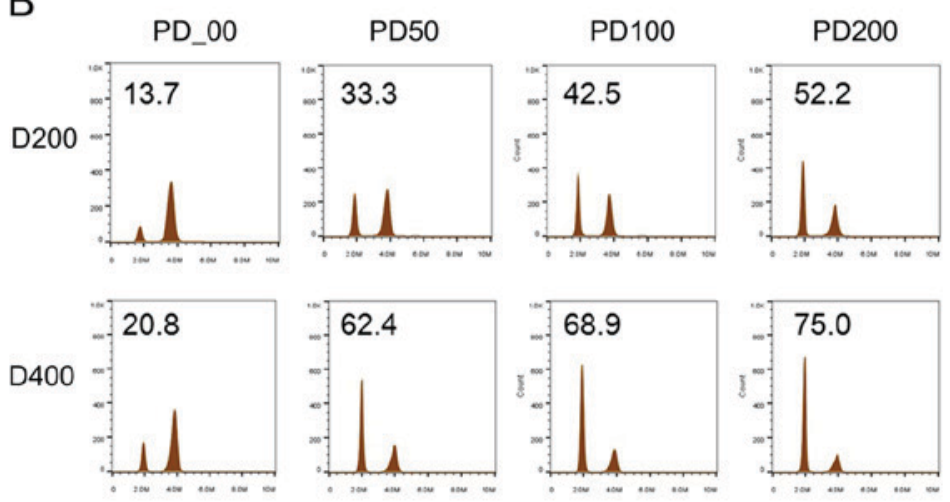

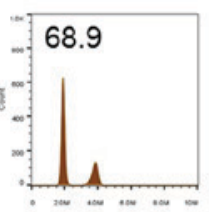

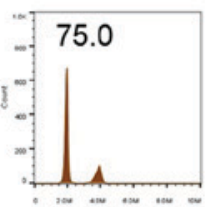

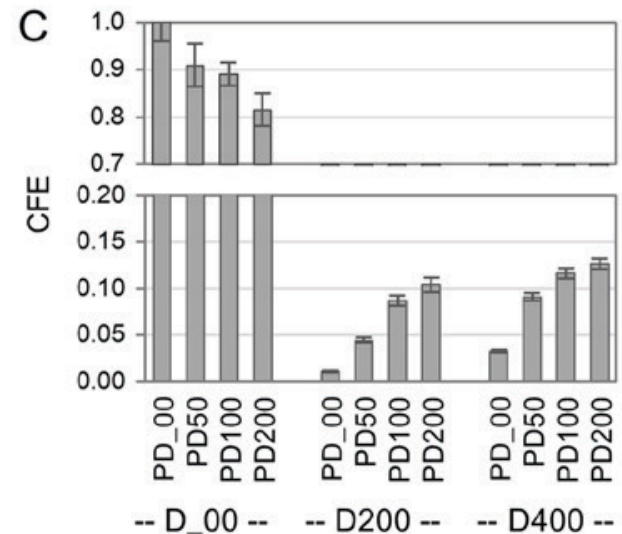

Figure 4. Co-treatment of PD0332991 with DOX in growing cells enhances colony formation in induced senescence. (A) Analysis of cell cycle arrest by PD0332991. Growing cells were treated with PD0332991 at indicated concentrations for $24 \mathrm{~h}$ in the presence/absence of NOC, and the cell cycle distribution was analyzed by flow cytometry. (B) DOX-induced $\mathrm{G}_{1}$ arrest affected by PD0332991. Growing cells were treated with PD0332991 and DOX for 24 h, and the cell cycle distribution was analyzed by flow cytometry. The numbers in histograms indicate percentages of $\mathrm{G}_{1}$ cells. (C) CFEs. Following a 24-h incubation of growing cells in PD0332991 and DOX, the cells were further incubated in drug-free medium to induce senescence. Following a 14-day incubation, CFEs were determined. Vertical and horizontal axes in histograms in (A) and (B) are DNA content and cell count, respectively. NOC, nocodazole; CFE, colony formation efficiency; DOX, doxorubicin.

presence of PD0332991. As hypothesized, cell cycle arrest in the $G_{1}$ phase was enhanced when co-treated with PD0332991 (Fig. 3B). As a result of this treatment, CFE was augmented (Fig. 3C). Collectively, slow progression of the cell cycle in the $G_{1}$ phase led to an increase in $G_{1}$-treated $G_{1}$-arrested cells and CFE.

Co-treatment of PD0332991 with DOX in growing cells enhances colony formation in induced senescence. The effects of PD0332991 on CFE were further examined using growing cells. Cells were treated with PD0332991 at concentrations from 50 to $800 \mathrm{nM}$ for $24 \mathrm{~h}$ and cell cycle distributions with or without nocodazole were examined (Fig. 4A). Cells accumulated in the $\mathrm{G}_{1}$ phase by PD0332991 treatment. Even at a $50 \mathrm{nM}$ concentration of PD0332991, the accumulation of cells in the $G_{1}$ phase was clearly detected. However, these $\mathrm{G}_{1}$ accumulations were abolished in the presence of nocodazole, indicating that the $\mathrm{G}_{1}$ accumulations did not result from complete cell cycle arrest, but rather a slow cell cycle progression in the $G_{1}$ phase. Next, senescence was induced in growing cells by a 24-h DOX treatment in the presence of PD0332991. The majority of cells ( $90 \%)$ exhibited SA- $\beta-\mathrm{Gal}$, comparable to that of sole treatment with DOX. However, an increased number of colonies appeared in induced senescence by co-treatment with DOX and PD0332991, and the increase in CFE was highly correlated with the increase in $\mathrm{G}_{1}$-arrested cells by the treatment $(r=0.746, n=6, P=0.088457$ from the overall analysis of D200 and D400 data) (Fig. 4B and C). Even in growing cells, PD0332991 enhanced the colony formation ability in DOX-induced senescence.

\section{Discussion}

The present study describes the relevance of $G_{1}$-treated $G_{1}$-arrested cells to colony formation in DOX-induced cellular senescence by increasing/decreasing $G_{1}$-treated $G_{1}$-arrested cells using three different procedures, Pre-REL, Post-REL and STD. The Pre-REL procedure increased $\mathrm{G}_{1}$-treated $\mathrm{G}_{1}$-arrested cells and enhanced CFE. Conversely, the Post-REL procedure decreased $\mathrm{G}_{1}$-treated $\mathrm{G}_{1}$-arrested cells and reduced CFE. Furthermore, the ratio of $G_{1}$-treated $G_{1}$-arrested cells was positively associated with the number of colony-forming cells. Therefore, it is likely that the colony formation ability is conferred by the $G_{1}$ arrest of cells treated by DOX in the $\mathrm{G}_{1}$ phase.

Cell clusters consisting of $<15$ cells were detected as early as 2-3 days after DOX treatment in the Pre-REL procedure. These cells were SA- $\beta$-Gal-negative. The cell clusters were detected as colonies in the subsequent incubation. This suggested that these colonies were formed from cells that had escaped from entering senescence during the treatment. It is likely that these colonies were the result of treatment conditions, leading to an increase in $\mathrm{G}_{1}$-treated $\mathrm{G}_{1}$-arrested cells.

DOX induces DNA damage and, in turn, the DNA damage has been demonstrated to activate the $G_{1}$ and $G_{2} / M$ checkpoints, 
which induces cell cycle arrest $(27,28)$. During cell cycle arrest, DNA damage is repaired and the cell cycle resumes following the completion of the repair. However, cells undergo senescence or apoptosis when the damage is extensive and not repairable. The present study observed cell cycle arrest in the $G_{1}$ and $\mathrm{G}_{2} / \mathrm{M}$ phases following treatment with DOX. These arrests are likely induced by the $G_{1}$ and $G_{2} / M$ checkpoints, respectively. Treatment of $\mathrm{G}_{1}$ phase cells, synchronized by serum starvation, with DOX also induced cell cycle arrest in the $\mathrm{G}_{1}$ and $\mathrm{G}_{2} / \mathrm{M}$ phases. The immediate $\mathrm{G}_{1}$ arrest by DOX treatment of $\mathrm{G}_{1}$ phase cells can act to protect cells from further damage received in the subsequent $S$ and $G_{2}$ phases. $G_{1}$ arrest has been reported to protect cells from drugs that selectively kill dividing cells $(29,30)$ Therefore, the immediate $\mathrm{G}_{1}$-treated $\mathrm{G}_{1}$ arrest would increase arresting cells with less and repairable damage. Following the removal of DOX, such cells can restart the cell cycle and form colonies. The colonies detected in the present study following treatment with DOX are hypothesized to be colonies that have resulted from the transiently arrested cells, which have restarted their cell cycle. Therefore, an increase of cells in the $G_{1}$ phase at treatment with DOX may lead to an increase in SECs.

The treatment of HCT116 cells with PD0332991, a cell cycle inhibitor, resulted in the accumulation of cells in the $\mathrm{G}_{1}$ phase. However, the accumulation of $\mathrm{G}_{1}$ cells did not result from complete arrest of the cell cycle in the $G_{1}$ phase, but was in fact from the slow cell cycle progression of cells in the $G_{1}$ phase. This may explain why the present study failed to induce senescence in cells treated with PD0332991, as the induction of senescence is known to require complete cell cycle arrest $(20,21)$. No enhancement of DOX-induced senescence was observed by co-treatment of PD0332991. On the contrary, the co-treatment of PD0332991 with DOX augmented the number of $\mathrm{G}_{1}$-treated $\mathrm{G}_{1}$-arrested cells, resulting in an increase in the number of colonies appearing in DOX-induced senescence. For the efficient induction of senescence, by reducing the number of SECs, it is necessary to avoid drug treatment of $\mathrm{G}_{1}$ phase cells. On this basis, caution would be advised when a drug like PD0332991, a cell cycle inhibitor, which potentially increases the cell population in the $\mathrm{G}_{1}$ phase, is considered for treatment purposes.

\section{Acknowledgements}

The authors would like to thank Dr Junji Itou and Dr Fumiaki Sato (Department of Breast Surgery, Kyoto University, Kyoto, Japan) and Dr Keiko Iwaisako (Department of Target Oncology, Kyoto University) for supplying the materials used in the study. The authors would also like to thank the members of the Breast Surgery Laboratory for useful discussion and suggestions, and Dr Ravi Velaga (Department of Breast Surgery, Kyoto University) for critically revising the manuscript.

\section{Funding}

No funding was received.

\section{Availability of data and materials}

All data generated or analyzed during this study are included in this published article.

\section{Authors' contributions}

KK designed the study, performed experiments and wrote the manuscript. FP conducted experiments. MT designed the study and wrote the manuscript. All authors read and approved the final manuscript.

\section{Ethics approval and consent to participate}

Not applicable.

\section{Patient consent for publication}

Not applicable.

\section{Competing interests}

The authors declare that they have no competing interests.

\section{References}

1. Campisi J: Senescent cells, tumor suppression, and organismal aging: Good citizens, bad neighbors. Cell 120: 513-522, 2005

2. Collado $\mathrm{M}$ and Serrano M: The power and the promise of oncogene-induced senescence markers. Nat Rev Cancer 6: 472-476, 2006

3. Di Mitri D and Alimonti A: Non-cell-autonomous regulation of cellular senescence in cancer. Trends Cell Biol 26: 215-226, 2016.

4. Wang X, Tsao SW, Wong YC and Cheung AL: Induction of senescent-like growth arrest as a new target in anticancer treatment. Curr Cancer Drug Targets 3: 153-159, 2003.

5. Tchkonia T, Zhu Y, van Deursen J, Campisi J and Kirkland JL: Cellular senescence and the senescent secretory phenotype: Therapeutic opportunities. J Clin Invest 123: 966-972, 2013.

6. Ewald JA, Desotelle JA, Wilding G and Jarrard DF: Therapyinduced senescence in cancer. J Natl Cancer Inst 102: 1536-1546, 2010.

7. Petrova NV, Velichko AK, Razin SV and Kantidze OL: Small molecule compounds that induce cellular senescence. Aging Cell 15: 999-1017, 2016.

8. Elmore LW, RehderCW,Di X, McChesney PA, Jackson-Cook CK, Gewirtz DA and Holt SE: Adriamycin-induced senescence in breast tumor cells involves functional p53 and telomere dysfunction. J Biol Chem 277: 35509-35515, 2002.

9. Sliwinska MA, Mosieniak G, Wolanin K, Babik A, Piwocka K, Magalska A, Szczepanowska J, Fronk J and Sikora E: Induction of senescence with doxorubicin leads to increased genomic instability of HCT116 cells. Mech Ageing Dev 130: 24-32, 2009.

10. Su D, Zhu S, Han X, Feng Y, Huang H, Ren G, Pan L, Zhang Y, Lu J and Huang B: BMP4-Smad signaling pathway mediates adriamycin-induced premature senescence in lung cancer cells. J Biol Chem 284: 12153-12164, 2009.

11. Hamilton E and Infante JR: Targeting CDK4/6 in patients with cancer. Cancer Treat Rev 45: 129-138, 2016.

12. Xu H, Yu S, Liu Q, Yuan X, Mani S, Pestell RG and Wu K: Recent advances of highly selective CDK4/6 inhibitors in breast cancer. J Hematol Oncol 10: 97, 2017.

13. Sherr CJ and Roberts JM: CDK inhibitors: Positive and negative regulators of G1-phase progression. Genes Dev 13: 1501-1512, 1999.

14. Malumbres M, Ortega S and Barbacid M: Genetic analysis of mammalian cyclin-dependent kinases and their inhibitors. Biol Chem 381: 827-838, 2000.

15. Fry DW, Harvey PJ, Keller PR, Elliott WL, Meade M, Trachet E, Albassam M, Zheng X, Leopold WR, Pryer NK, et al: Specific inhibition of cyclin-dependent kinase 4/6 by PD 0332991 and associated antitumor activity in human tumor xenografts. Mol Cancer Ther 3: 1427-1438, 2004.

16. Toogood PL, Harvey PJ, Repine JT, Sheehan DJ, VanderWel SN, Zhou H, Keller PR, McNamara DJ, Sherry D, Zhu T, et al: Discovery of a potent and selective inhibitor of cyclin-dependent kinase 4/6. J Med Chem 48: 2388-2406, 2005. 
17. Guha M: Cyclin-dependent kinase inhibitors move into Phase III. Nat Rev Drug Discov 11: 892-894, 2012.

18. Kovatcheva M, Liu DD, Dickson MA, Klein ME, O'Connor R, Wilder FO, Socci ND, Tap WD, Schwartz GK, Singer S, et al: MDM2 turnover and expression of ATRX determine the choice between quiescence and senescence in response to CDK4 inhibition. Oncotarget 6: 8226-8243, 2015.

19. Ziemke EK, Dosch JS, Maust JD, Shettigar A, Sen A, Welling TH, Hardiman KM and Sebolt-Leopold JS: Sensitivity of KRASmutant colorectal cancers to combination therapy that cotargets MEK and CDK4/6. Clin Cancer Res 22: 405-414, 2016.

20. Chang BD, Xuan Y, Broude EV, Zhu H, Schott B, Fang J and Roninson IB: Role of p53 and p21waf1/cip1 in senescence-like terminal proliferation arrest induced in human tumor cells by chemotherapeutic drugs. Oncogene 18: 4808-4818, 1999.

21. Ben-Porath I and Weinberg RA: The signals and pathways activating cellular senescence. Int J Biochem Cell Biol 37: 961-976, 2005.

22. Dimri GP, Lee X, Basile G, Acosta M, Scott G, Roskelley C, Medrano EE, Linskens M, Rubelj I and Pereira-Smith O: A biomarker that identifies senescent human cells in culture and in aging skin in vivo. Proc Natl Acad Sci USA 92: 9363-9367, 1995.

23. Trzepacz C, Lowy AM, Kordich JJ and Groden J: Phosphorylation of the tumor suppressor adenomatous polyposis coli (APC) by the cyclin-dependent kinase p34. J Biol Chem 272: 21681-21684, 1997.

24. Mizuno H, Nakanishi Y, Ishii N, Sarai A and Kitada K: A signature-based method for indexing cell cycle phase distribution from microarray profiles. BMC Genomics 10: 137, 2009.
25. Zieve GW, Turnbull D, Mullins JM and McIntosh JR: Production of large numbers of mitotic mammalian cells by use of the reversible microtubule inhibitor nocodazole. Nocodazole accumulated mitotic cells. Exp Cell Res 126: 397-405, 1980.

26. Long BH and Fairchild CR: Paclitaxel inhibits progression of mitotic cells to G1 phase by interference with spindle formation without affecting other microtubule functions during anaphase and telephase. Cancer Res 54: 4355-4361, 1994.

27. Erol A: Deciphering the intricate regulatory mechanisms for the cellular choice between cell repair, apoptosis or senescence in response to damaging signals. Cell Signal 23: 1076-1081, 2011.

28. Roos WP, Thomas AD and Kaina B: DNA damage and the balance between survival and death in cancer biology. Nat Rev Cancer 16: 20-33, 2016.

29. Chen X, Lowe M, Herliczek T, Hall MJ, Danes C, Lawrence DA and Keyomarsi K: Protection of normal proliferating cells against chemotherapy by staurosporine-mediated, selective, and reversible G(1) arrest. J Natl Cancer Inst 92: 1999-2008, 2000

30. Blagosklonny MV and Pardee AB: Exploiting cancer cell cycling for selective protection of normal cells. Cancer Res 61: 4301-4305, 2001.

This work is licensed under a Creative Commons Attribution-NonCommercial-NoDerivatives 4.0 International (CC BY-NC-ND 4.0) License. 